\title{
Spatial and temporal drought incidence analysis in the northeastern highlands of Ethiopia
}

\author{
Abebe Arega Mekonen ${ }^{*}$ (D, Arega Bazezew Berlie and Mehrete Belay Ferede
}

\begin{abstract}
This study investigated the space-time drought incidence in the northeastern highlands of Ethiopia using monthly rainfall data. It also aims to predict drought events for 100 years. The Standardized Precipitation Index (SPI) was used to compute the drought severity classes of rainy months and seasons at 1-, 4- and 8-months timesteps. The Mann-Kendall's test and Sen's slope estimator were used to analyze the trends of drought events and to determine the magnitude of change. Inverse Distance Weighted spatial analysis tool was used to illustrate the spatial patterns of the drought risk events. The study detected extreme severe droughts in the belg rainy months in March 2008 and April 1984. However, during the belg season, the year 1999 was the driest for the recorded periods. On the other hand, the extremely severe droughts were observed during the kiremt rainy months of July 1987 and 2015, August 1984, and September 2009. In general, 1984, 1987 and 2015 were the driest years recorded in the kiremt season. The study noted that the drought risk events of months in the belg season were threefold greater than that of the months in kiremt season under moderate drought intensity class. Equally, the drought risk events of months in kiremt season were threefold greater than that of the belg season under extreme drought intensity class. Complex spatial variations of drought risk events were also observed in 1-, 4- and 8-months timesteps. During the belg seasons, the southern half was subjected to more frequent drought risk events while the northern half experienced more frequent drought risk events during kiremt season. Almost the eastern half of the livelihood zones experienced higher drought frequency events than the other parts in the 8-month timestep. The observed space-time drought risk event analysis has shown a potential threat to the rainfed agricultural practices that have a great influence on the livelihoods of smallholder farmers. Hence, documentation and assessment of drought risk events based on the livelihood zones are essential for drought risk management, early warning responses, localscale planning and food security management. Finally, the study recommended further research on additional indices of climatic variables such as evapotranspiration and soil water content.
\end{abstract}

Keywords: Livelihood zone, Belg and kiremt, Drought, Standardized precipitation index, South Wollo, Ethiopia

\section{Introduction}

Drought is a commonly used term, but the most complex and least realized of all the natural hazards affecting more people than any other hazards (Wilhite 2000; Ashraf and Routray 2013). As opposed to other extreme events, (like floods, tornadoes, and hurricanes), drought develops slowly and steadily, making it difficult to determine the onset and end (WMO 2016). Generally, drought is related to a continual deficit of water below

\footnotetext{
* Correspondence: abebemekkon@gmail.com

Department of Geography and Environmental Studies, Bahir Dar University, P.O. Box 79, Bahir Dar, Ethiopia
}

average usually for a season or more (AghaKouchak and Nakhjiri 2012; Guha-Sapir et al. 2012; Dai 2011; Ashraf and Routray 2013; WFP 2014). Many scholars, for instance, AghaKouchak and Nakhjiri (2012), Jeyaseelan (2003) and Wilhite and Glantz (1985) classified drought as meteorological, hydrological, agricultural, and socioeconomic based on the causative factors. These drought types share the deficiency of precipitation as a common phenomenon. Among these, the meteorological drought is the main driver; leading to the more likely occurrences of agricultural and hydrological droughts (WMO 2016; Zhan et al. 2016; Mpelasoka et al. 2008). 
Since drought is a recurrent climatic phenomenon, its outcome is manifested through immense damage to agriculture production, reduction of water supply and energy production, mass migration and loss of life (Masih et al. 2014). Writers such as -Sheffield and Wood (2007), Bannayan et al. (2010), and Degefu and Bewket (2015) differently showed that the causes and influences of drought in space-time on the environment are determined by the attributes of frequency, magnitude, intensity, and spatial extent. Likewise, Trenberth et al. (2011) reported that the magnitude, intensity, frequency and spatial coverage of the dry area has been doubled since the 1970s in Africa, East and South Asia, eastern Australia, Southern Europe, Northern and Southern America, most of Alaska, and Western Canada. Within the period 1960-2016, there were about 669 drought events reported across the world, and hence it has killed about 2.2 million people and affected over 2.6 billion people and an estimated economic damage of 146 billion US Dolar Centre for Research on the Epidemiology of Disasters/CRED (2016).

The vulnerability of developing countries to drought has risen by a factor of three in the decade of the 1990s compared with the 1960s (Mirza 2003). Much of the northern, southern, eastern and Sahelian African countries experienced the worst droughts in terms of the number of people killed and affected in 1972/73 and 1984/85 (Gommes and Petrassi 1996). For instance, of all the natural disasters, droughts account for only $8 \%$ of the global phenomenon. It also accounts for $25 \%$ in Africa between 1960 and 2006 (Gautam 2006). In the 1980s drought killed more than half of a million people in Africa (Dai 2011). In Sub Saharan African countries, crop production and food security are mainly threatened by drought where the effects are inter-temporal and long-lasting (Shiferaw et al. 2014). Africa stands first with a total of 289 reported the number of drought events that killed almost 700 thousand people and affected above 414 million people between 1960 and 2016 due to the induced drought frequency (Centre for Research on the Epidemiology of Disasters/CRED 2016).

Drought has a severe negative impact on key socioeconomic sectors of most Eastern African countries (Butterfield 2011). Its incidence has increased steadily in East Africa for the last five decades (Gautam 2006). For instance, deprivation associated with drought and food crises disaster victims for East African countries (Burundi, Djibouti, Ethiopia, Kenya, Somalia, and Uganda) increased from one million people in the 1980 s to 21 million in the 2010s (Hao et al. 2014; Guha-Sapir et al. 2012).

In Ethiopia, extreme weather events owing to insufficient total rainfall amount and long dry periods affected the agro-socioeconomic environment in the northern, southern and eastern parts of the country and resulted in great human sufferings and losses of life (Seleshi and Camberlin 2006). Precipitation exhibits great spatial variation both in annual average and inter-annually that could be taken as the major cause for the occurrence of the droughts in the country (Viste et al. 2013; World Bank 2006a, 2006b). In this regard, Viste et al. (2013) conclude that there are no years without drought in many parts of Ethiopia. Consequently, environmental and socioeconomic deprivation in Ethiopia happened due to the cumulative induced drought over several crisis seasons (Endale 1993). In the future, due to the increasing resource depletion, single-year droughts may be sufficient to cause severe hardship among vulnerable households (Webb and Von Braun 1990; Webb and Braun 1994).

Although the name "Water Tower of North-East Africa" has been given to Ethiopia, the country is one of the Horn countries highly vulnerable to drought (Gebrehiwot et al. 2011). The history of drought and associated disasters in Ethiopia traced back to 250 B.C. with a total of 39 periods of food shortage and excess mortality rate have been identified (Block 2008; Webb and Von Braun 1990; Webb and Braun 1994; Webb et al. 1992). Impacts of droughts in Ethiopia are perhaps the most widely publicized given their severity and frequency (Gautam 2006). As recent literature ratifies, Ethiopia's history has been periodically marked by major drought incidences for the period 1950-2016 (Table 1).

Drought frequency in Ethiopia has been increasing. For example, in the 1970s and 1980s drought usually occurred once per decade (Block 2008; United Nations Environment Program/UNEP 2011). It was also about twice every 3 years between 1980 and 2004 (World Bank 2006a, 2006b) and once a year between the 1990s and 2011 (Viste et al. 2013). The estimated human cost caused by drought in Ethiopia between 1972 and 1984 were about 1.2 million people (United Nations Environment Program/UNEP 2002). These evidences showed that Ethiopia is often stricken by droughts in the 1970s and 1980s resulted in widespread poverty, economic stagnation, depletion of household assets and savings, and excess mortality (Dorosh and Rashid 2013). South Wollo, located in the northeastern highlands of Ethiopia is an epicenter for drought and famine for many years. The zone is a drought prone area and faces the horrible combination of both high risk and low potential as well as chronic food insecurity (World Bank 2006a, 2006b).

Of the total recorded drought years (1953-2016) in Ethiopia, Wollo experienced about $72 \%$ of the drought events (Little et al. 2006). In fact, the existence of diverse agroecology enables the zone to raise different types of livestock and to produce cash and food crops (ANRSPC 2017; 2018). But, the agricultural activities are entirely rainfed except in a few localities where there are small- 
Table 1 Reported drought years, regions affected, causes and severities since the 1960s in Ethiopia

\begin{tabular}{|c|c|c|}
\hline Year & Region Affected & Causes and severity description \\
\hline $1957 / 58$ & Tigray and Wollo & Rain failure in 1957; locusts and epidemic in 1958 and about 100,000 people died \\
\hline 1962/63 & Western Ethiopia & Very severe \\
\hline 1964-66 & Tigray and Wollo & About 1.5 million people were affected and about 300, 000 livestock died \\
\hline $1971-75$ & Ethiopia & $\begin{array}{l}\text { Sequence of rain failures; estimated } 250,000 \text { dead; } 50 \% \text { of livestock lost in } \\
\text { Tigray and Wollo }\end{array}$ \\
\hline 1978/79 & Southern Ethiopia & Failure of Belg rain \& 1.4 million people were affected \\
\hline 1982 & Northern Ethiopia & Late Meher rains \& 2 million people were affected \\
\hline 1984/85 & Ethiopia & Sequential rain failure; 8 million people affected; \\
\hline 1987/88 & Ethiopia & 7 million people were affected \\
\hline 1990-92 & Northern, Eastern, and SW Ethiopia & $\begin{array}{l}\text { Rain failure and regional conflicts; estimated } 4 \text { million people suffering food } \\
\text { shortage }\end{array}$ \\
\hline 1993/94 & Tigray and Wollo & $\begin{array}{l}\text { Widespread food insecurity ( } 7.6 \text { million people were affected), but few deaths } \\
\text { or cases of displacement were reported. }\end{array}$ \\
\hline 1997 & Borena, Bale, Omo, Somali & Almost 986, 000 people affected \\
\hline 1999 & $\begin{array}{l}\text { N. \& S. Wollo, Wag, Himra; Tigray; B. Gumu, } \\
\text { Gambela, Oromia, SNNPR, Somali }\end{array}$ & Almost 5 million people affected \\
\hline $2003 / 4$ & All Regions & $\begin{array}{l}\text { Over } 13 \text { million people affected, but the response mitigated the worst } \\
\text { potential outcomes. }\end{array}$ \\
\hline 2005 & Somali, Oromia & Almost 2.6 million drought disaster affected people \\
\hline $2008 / 9$ & All regions & Almost 12.6 million People were affected. \\
\hline 2011 & S \& E. Oromia, Somali & Severe food insecurity and 4 million people affected \\
\hline 2015/16 & N., E, \& SW Ethiopia & About 10.2 million people were affected \\
\hline
\end{tabular}

Source: Degefu 1987; Webb and Von Braun 1990; Webb and Braun 1994; Webb et al. 1992; Philip et al. 2017

scale irrigation and water harvesting practices (SWAD 2018). Dominant cereal crops produced in the region include teff (Eragrostis tef), sorghum (Sorghum bicolor), maize (Zea mays), wheat (Triticum aestivum), barley (Hordeum vulgare) and pulses (Leguminosae/ Fabaceae). Nevertheless, the larger reliance on agriculture-based income, which is under the sensitivity of nature exposed the people to food deficiency (Little et al. 2006; Kahsay 2013). All these attributes contributed to the reduction of productivity in the zone. This might be the reason that the zone is exposed to food shortage and dependent on safety nets for many years. Therefore, an assessment of the spatio-temporal drought risk events is imperative for policy makers and practitioners in the area under study.

The classification and representation of observed spatio-temporal drought risk events using SPI are vital in operational monitoring for policy decisions. Accordingly, many studies, but different in study periods and spatial coverage related to drought were documented in Ethiopia using SPI (e.g. Suryabhagavan 2017; Degefu and Bewket 2015; Viste et al. 2013; Gebrehiwot et al. 2011; Williams and Funk 2011; Edossa et al. 2010; Korecha and Barnston 2007; Segele and Lamb 2005; Seleshi and Zanke 2004). Many of these studies documented either temporal or spatial or both to show the most common
SPI-values of 3-, 6-, 9-, 12-, and 24-months timesteps. However, the SPI can be computed at any timescales for any set of successive months of 1-month up to 72months. The spatial and temporal drought event analysis for SPI 1-, 4- and 8-months timesteps are not included in their studies. Therefore, the analysis of the space-time pattern of drought risk events of this study is based on the rainy months and seasons of 1-, 4- and 8-months timesteps. The space-time drought risk events of the small and big rainy months as well as seasons (SPI: 1-, 4- and 8months timesteps) are appropriate for planning and management of drought and related risks at the local-scale level. This study, therefore, aims to characterize the spatial and temporal drought incidences as a function of frequency, magnitude, intensity and severity status using the SPI model over the northeastern highlands of Ethiopia.

\section{Drought quantification: the standardized precipitation index}

Drought indices are essential to characterize several drought features such as the onset and cease time of drought, drought duration, areal extent, severity and frequency at global, regional and local level (Piechota and Dracup 1996). Owing to the complexity of drought, numerous operational drought indices have been developed and used by meteorologists and climatologists around 
the world (WMO 2016; Dai 2011). In the international works of literature, a large number of studies acknowledge numerous indices in the detection, analysis, and monitoring of drought events for recent and projected changes (Loukas and Vasiliades 2004). Among the numerous indices, the most commonly used drought index with its strengths and weaknesses is the Standardized Precipitation Index (SPI) (McKee et al. 1993).

The SPI is relatively new application, gaining worldwide acceptance and widely used at present because of its powerfulness, effectiveness, flexibility, versatile and standardized nature (Beth and Brown 2003; WMO 2012; Tsakiris and Vangelis 2004; Mashari Eshghabad et al. 2014). Hence, choosing a precipitation-based drought measure (SPI model) is preferred for its low data requirement and computational simplicity for developing countries like Ethiopia where the access to data is limited (Viste et al. 2013; Degefu and Bewket 2015).

SPI values in one region can be directly compared to SPI values in a completely different climate zone. It can monitor the onset, intensity, and duration of drought (Hayes et al. 1999; Loukas and Vasiliades 2004). The SPI is a very suitable index to study the geospatial and temporal variation of drought with spatially invariable results for historic time series analysis (Masih et al. 2014; Guttman 1998). The ideal strength of SPI is that precipitation anomalies can be consistently calculated over flexible time scales in a consistent fashion. Similarly, drought information can be provided promptly for operational drought-monitoring applications (AghaKouchak and Nakhjiri 2012). Even, following the discussion at (WMO 2009), drought experts made a consensus agreement to recommend the SPI for the characterization of meteorological droughts (Hayes et al. 2011). The SPI measures moisture to quantify the precipitation deficit for multiple time scales at any one location and reflects the impact of drought on a range of meteorological, agricultural and hydrological applications (Marimon 2016; Degefu and Bewket 2015; Loukas and Vasiliades 2004). The SPI can be calculated at various timescales for any set of successive months of 1-month up to 72-months that one wishes to detect and to illustrate the effect of drought (Viste et al. 2013; Stagge et al. 2015; Padhee et al. 2014; Beth and Brown 2003; AghaKouchak and Nakhjiri 2012). But statistically, 1-24 months is the best practice range of application (Guttman 1999). The short period time scales SPI-values (1-, 2-, 3-, 4-, 5- and 6months) are appropriate and paramount for measuring the effect of drought on agriculture, soil moisture and crop yield reduction (Bussay et al. 1998; Morid et al. 2006; Szalai and Szinell 2000).

A 3-month SPI reflects short- and medium-term moisture conditions and provides a seasonal estimation of precipitation. In primary agricultural regions, a 3-month
SPI might be more effective in highlighting available moisture conditions than the slow-responding Palmer Index or other currently available indices (WMO 2012). As compared to other indices, SPI is an appropriate index for drought analysis to East African countries indicated by various studies. For instance, Ntale and Gan (2003) suggested that SPI is more suitable for monitoring droughts in East Africa because (i) it is easily adapted to the local climate, (ii) it needs a modest data requirement, (iii) it produces spatially consistent results, and (iv) it can be computed almost at any time scale.

\section{Materials and methods}

\section{Description of the study site}

South Wollo is one of the eleven administrative zones of the Amhara National Regional State which is located between $10^{\circ} 10^{\prime} \mathrm{N}$ and $11^{\circ} 41^{\prime} \mathrm{N}$ latitudes and $38^{\circ} 28^{\prime} \mathrm{E}$ and $40^{0} 5^{\prime} \mathrm{E}$ longitudes (Fig. 1). The total area of the Zone is about $18,157.48 \mathrm{~km}^{2}$, which is divided into 19 rural districts and four administrative towns (Dessie, Kombolcha, Haik, and Mekaneselam) (ANRSPC 2017). Of the total area, $36.3 \%, 13.5 \%, 18.3 \%$ and $31.9 \%$ are covered by arable land, forest and bush lands, grazing land, and others (e.g. bare land, buildings, water bodies), respectively (SWAD 2018). The landscape of the South Wollo zone comprises highly diversified and dissected topography (rugged terrain with very steep slopes). Elevation ranges from $927 \mathrm{~m}$ (over the dry plain/Arabat) in the east to $4261 \mathrm{~m}$ above sea level (Mount Ambaferit) in the west (SWAD 2018; Little et al. 2006). It has six livelihood zones, namely, Abay-Beshilo Basin (ABB), Chefa Valley (CHV), Meher-Belg zone, Belg zone, Meher zone and eastern lowland sorghum and cattle (SWS) (USAID 2009).

The Zone is characterized by a distinctive bi-modal rainfall regime, locally known as kiremt and belg seasons. Kiremt is the big rainy season usually extending from June-to-September, and belg is the small rainy season extending from February-to-May (National Meteorological Services Agency of Ethiopia/NMSA 1996; Degefu 1987; Korecha and Barnston 2007; Conway 2000a, 2000b). Crop production in the entire livelihood zones follow these rainfall regimes but varies among the livelihood zones. Accordingly, the livelihood zones of ABB, SWS Meher and CHV are dependent on big kiremt rainfall for the cultivation of both long and short cycle crop production. Conversely, Belg and Meher-Belg crop productions follow the bimodal rainfall regimes (the small belg and big kiremt rains) leading to two harvest periods. The mean annual rainfall ranges between 500 and 900 $\mathrm{mm}$ in the Kolla (arid and semi-arid) area and 950$1100 \mathrm{~mm}$ in the Woina Dega (semi-humid) and Dega (cool and humid) areas. The average annual temperature also ranges from $15^{\circ} \mathrm{C}$ to $20^{\circ} \mathrm{C}$ (SWAD 2018). Between 1901 to 2016 the minimum temperature ranges were 


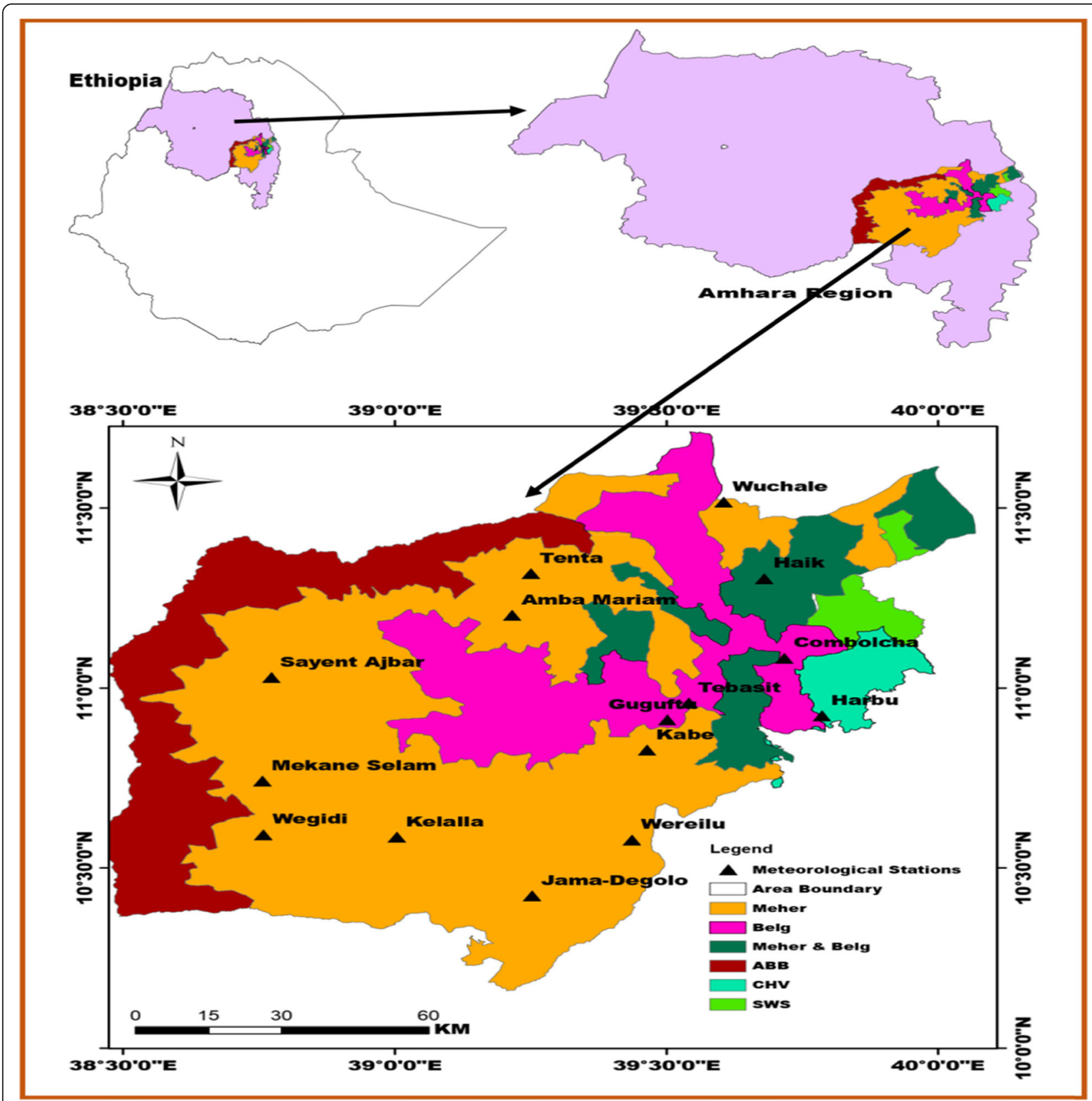

Fig. 1 The geographic location of livelihood zones of South Wollo and Meteorological stations. Source: Extracted from USAID 2009

$6.43^{\circ} \mathrm{C}$ in December and $11.82^{\circ} \mathrm{C}$ in June while the maximum ranges were $22.93^{\circ} \mathrm{C}$ in August and December and $29.13^{\circ} \mathrm{C}$ in June.

Based on the population statistics of ANRSPC (2017), the South Wollo zone has a total population of nearly 3.1 million of whom $49.5 \%$ were males and $50.5 \%$ females. The zone is one of the densely populated areas of the country with 171 persons per $\mathrm{km}^{2}$. The old-style subsistence farming (a mix of both grain production and rearing of livestock) is the primary form of economic activity in all livelihood zone of the study area (ANRSPC 2017; SWAD 2018). Even though the small and large-scale irrigation practices are very minimal, the zone is known by many large and small rivers categorized into two major drainage basins (Abay and Awash accounting for about $82 \%$ and $18 \%$ of the area, respectively) (SWAD 2018). Cattle, goats, sheep, and equines are the major livestock in the area. However, the contribution of livestock to the livelihood of the people is constrained by the prevalence of livestock diseases (USAID 2009; Little et al. 2006). 


\section{Data sources and data analysis techniques}

For the characterization of spatial and temporal drought incidences as a function of frequency, magnitude, intensity, and severity status, long-term meteorological data were acquired from the Ethiopian National Meteorological Agency (ENMA-Kombolcha Regional Meteorological Station). Since rainfall is not normally distributed, a gamma probability distribution has been found fitting to the precipitation time series frequency distribution for the computation of SPI (Khan and Gadiwala 2013). The gamma probability density function is expected to fit with the frequency distribution of precipitation over the period (1981-2017). For the time scales of 1-, 4- and 8- months, alpha $(\alpha)$ and beta $(\beta)$ parameters of the gamma probability density function were estimated. As a result, the cumulative probability distribution function is approximated into the standard normal cumulative distribution probability function with a mean of zero and a standard deviation of one to determine the probability distribution function. Conceptually, the SPI is equivalent to Z- score, the number of standard deviations that the observed value would deviate from the long-term mean. The statistical procedure is:

$$
\mathbf{S P I}=\frac{\mathbf{X}_{\mathbf{i}-} \bar{X}}{\sigma}
$$

Where: $\mathbf{x i}=$ observed precipitation value of the selected period during the $\mathrm{i}$ th year;

$\overline{\mathrm{X}}$ and $\boldsymbol{\sigma}=$ the mean and the standard deviation respectively over the selected period.

In this study, SPI was computed for shorter-term and intermediate periods to quantify drought events at 1-, 4and 8-months timesteps to represent agricultural/meteorological droughts. The 1-month SPI (analogous to the percent of normal precipitation) reflected short-term conditions of soil moisture and crop stress during the growing season while the 4-months SPI represented the short and medium-term moisture conditions applied for the seasonal estimation of rainfall. The 4-months accumulation of SPI was calculated for May and (September) to assess the seasonal drought of belg and (kiremt). This is because of the 4-month definition of seasons in Ethiopia are the most commonly used (Viste et al. 2013). The 8-months timestep accumulation of SPI was computed for September (February-to-September), which was also a good indicator to assess the drought condition of slowly maturing long-cycle crops like sorghum and maize that typically planted during the belg season and harvested following the kiremt season.

In the computation of SPI, the SPI_SL_6.exe file programming which was available at http://drought.unl.edu/ MonitoringTools/DownloadableSPIProgram.aspx has been employed. The criteria employed by McKee et al.
(1993) and WMO (2012), have been applied in the quantification and classification of SPI drought severity status of the study. In the computation of drought status classification of this study, only months with SPI $\leq-1.00$ were considered to be as drought initiation and cessation since mild drought (SPI between -0.99 and 0.99) showed only a slight variation from the normal rainfall distribution (Łabędzki 2007; Sternberg et al. 2011; Degefu and Bewket 2015). Therefore, using the SPI_SL_ 6.exe file programming, moderate drought (SPI between -1.00 and -1.49 ), severe drought (SPI between -1.50 and - 1.99) and extreme drought (SPI $\leq-2.00)$ were generated and presented in the form of time series graphs and maps.

Temporal drought event characteristics (frequency, magnitude, intensity and severity status) were computed using one of the most common models, SPI analysis parameters. Drought frequency is the return period between drought events that have severity threshold values of $\mathrm{SPI} \leq-1$. The magnitude of drought event corresponds to the cumulative water deficit during the drought period below some threshold (SPI-values $\geq-1$ ) (Thompson 1999) and drought intensity $\left(\mathbf{D}_{\mathbf{I}}\right)$ is the ratio between the drought magnitude and the duration of the event computed as:

$$
\begin{aligned}
& \mathbf{D}_{\mathbf{M}}=-\sum_{\mathbf{i}=\mathbf{1}}^{\mathbf{n}} \mathbf{S P I}_{\mathbf{i j}} \\
& \mathrm{D}_{\mathrm{I}}=\frac{\mathrm{D}_{\mathrm{M}}}{\mathrm{D}_{\mathrm{d}}}
\end{aligned}
$$

Where: $\mathbf{D}_{\mathbf{M}}=$ drought magnitude,

$\mathbf{n}=$ number of months with drought event at $\mathbf{j}$ timestep;

$\mathbf{D}_{\mathbf{d}}=$ drought duration .

However, drought severity $\left(\mathbf{D}_{\mathbf{S}}\right)$ should not be misguided for intensity, which is generally signified to the lowest SPI-value of the drought event (Spinoni et al. 2014). The number of droughts per 100 years for different timesteps of the rainy months and seasons (SPI:1-, 4- and 8-months) of the study as used by (Łabędzki 2007; Sternberg et al. 2011; Degefu and Bewket 2015; Ghosh 2019) which was estimated as:

$$
\mathrm{N}_{\mathrm{i}, 100}=\frac{\mathrm{N}_{\mathrm{i}}}{i \mathrm{X} \mathrm{n}} \mathrm{X100}
$$

Where:

$\mathrm{Ni}, 100=$ the number of droughts for a timestep $\mathrm{i}$ in 100 years;

$\mathrm{Ni}=$ the number of years with droughts for a timestep $i$ in the n-year set;

$\mathrm{i}=$ the timesteps (1-, 4- and 8- months) and.

$\mathrm{n}=$ the number of years in the data set (37 years). 
Furthermore, the MK (Mann Kendall) trend test (Kendall 1975; Mann 1945) has been computed to check the statistical significance (increasing and decreasing trends) for rainy months and seasons of SPI: 1-, 4- and 8months timesteps. The relative strength of $\mathrm{MK}$ trend test in time series analysis has been quantified using Sen's (1968) slope estimator. As indicated by Chattopadhyay and Edwards (2016), Sen's slope estimator has been the commonly used estimator due to its relative insensitivity and robustness to extreme values. The MK statistic $\mathbf{S}$ of the series $\mathbf{x}$ is calculated as:

$$
S=\sum_{i=1}^{N-1} \sum_{j=i+1}^{N} \operatorname{sgn}\left(X_{j-} X_{i}\right)
$$

Where:

$\mathrm{N}=$ the number of data points;

$X_{i}$ and $X_{j}=$ the time series observations. Assuming $\left(x_{j}\right.$ $\left.-x_{i}\right)=\theta$, the value of $\operatorname{sgn}(\theta)$ is computed from:

$$
\operatorname{sgn}(\theta)=\left\{\begin{array}{c}
+1 \ldots \ldots . . \theta>0 \\
0 \ldots \ldots . \theta=0 \\
-1 \ldots \ldots . . \theta<0
\end{array}\right.
$$

While Positive values of $\mathrm{S}$ indicate increasing trends, negative $\mathrm{S}$ indicates decreasing trends. Under the hypothesis of independent and randomly distributed random variables, for large samples, when $n \geq 10$ (in some papers $n \geq 8$ ), the $\sigma$ statistic is approximately normally distributed, with zero mean and variance as follows:

$$
\boldsymbol{\sigma}^{2}=\frac{\mathbf{n}(\mathbf{n}-\mathbf{1})(\mathbf{2 n}+5)}{18}
$$

As a consequence, the standardized normal deviate (Zstatistics) distribution has been then calculated as:

$$
Z=\left\{\begin{array}{l}
\frac{S-1}{\sigma} \text { if } S>0 \\
\mathbf{0} \text { if } S=0 \\
\frac{S+1}{\sigma} \text { if } S<0
\end{array}\right.
$$

While Positive values of $\mathrm{Z}$ signify increasing trends, negative $Z$ signifies decreasing trends. In the spatial analysis of drought severity status, Inverse Distance Weighted, IDW average interpolation method was used in the ArcGIS. The SPI values generated from SPI_SL_ 6.exe file programming was used as an input for mapping the spatial distribution of drought severity status. As a consequence, the 1-, 4- and 8-months timesteps spatial distributions of drought incidences were mapped.

\section{Results}

Characteristics of drought events: frequency, magnitude, intensity and severity

Table 2 shows the observed drought frequency, magnitude, intensity and severity of the small, big, and longterm rainy months and seasons as computed using SPI. The highest frequency of drought years for the small rainy months within the moderately to extremely dry $(\mathrm{SPI} \leq-1.00)$ found to be 9 years; in February and May account for about $24 \%$ of the total years over the study period. The drought magnitudes of the small rainy months were ranged from - 9.45 in March to - 11.83 in May. Nevertheless, the drought intensity found to be between the moderately dry in May with SPI $=-1.23$ and severely dry in March with SPI $=-1.58$. The extreme severe droughts were observed in March 2008 and April 1984 with the severity of peak SPI-values of -2.49 and -2.23 , respectively. Likewise, the highest drought frequency in the big rainy months was 6 years in June that account for $15 \%$ of the total drought risk years. The observed magnitude of drought events ranged from -9.7 in July to -5.69 in September. The moderately dry drought intensity was observed in June, July, and September while the extremely dry drought intensity was observed in August. The worst droughts were recorded in July 2015, August 1984, and September 2009 with the severity peak of SPI values of $2.82,-3.61$, and 2.31 , respectively.

Seasonally, the drought frequency for SPI 4-months of both belg and kiremt as well as long-term season of SPI 8-months at the end of May and September account for about 4 years $(9 \%)$ of the total drought years under study. A slight difference in the observed drought risk magnitude was shown among the SPI4-months (belg and kiremt) and SPI8-months (long-term) seasons. Nonetheless, the drought intensity was varied from severely dry in SPI4-months (belg) and SPI8-months (long-term) seasons with $\mathrm{SPI}=-1.92$ and -1.79 respectively to extremely dry in SPI4-months (kiremt) season with SPI = - 2.0. The SPI 4- and 8-months experienced severe drought events in 1984, 1999 and 2015 with severity peak SPI-values of $-2.83,-2.84$ and -2.32 , respectively.

\section{Temporal trends of drought events}

Using the SPI, the drought condition of the study for rainy months (SPI-1), belg and kiremt (SPI-4), and longterm (SPI-8) rainy seasons covering the period of 19812017 were examined. A mix of dry and wet years have been observed in February, March, April, and May as well as belg season but with temporal variation in severity, magnitude and intensity (Fig. 2a-d and Fig. 4a). Several drought risk incidences with $\mathrm{SPI} \leq-1.00$ were detected. It was observed that March 2008, April 1984, and the belg season of 1999 were characterized by extreme drought events with $\mathrm{SPI} \leq-2$ in the past 37 years. 
Table 2 Drought risk characteristics of the rainy months and seasons for SPI $\leq 1.0$ values

\begin{tabular}{|c|c|c|c|c|c|}
\hline \multirow[t]{3}{*}{ Month } & \multicolumn{5}{|c|}{ Observed Drought risk } \\
\hline & \multirow{2}{*}{$\begin{array}{l}\text { Frequency } \\
\text { (years) }\end{array}$} & \multirow[t]{2}{*}{ Magnitude } & \multirow[t]{2}{*}{ Intensity } & \multicolumn{2}{|l|}{ Severity } \\
\hline & & & & Peak SPI-Value & Year/s \\
\hline February & 9 & -10.92 & -1.23 & -1.32 & $1999,2000,2012$ \\
\hline March & 6 & -9.45 & -1.58 & -2.49 & 2008 \\
\hline April & 7 & -10.58 & -1.5 & -2.23 & 1984 \\
\hline May & 9 & -11.83 & -1.37 & -1.52 & 1981 \\
\hline Feb-to-May (Belg: SPI-4) & 4 & -7.66 & -1.92 & -2.84 & 1999 \\
\hline June & 6 & -7.3 & -1.22 & -1.78 & 1981 \\
\hline July & 5 & -9.7 & -1.94 & -2.82 & 2015 \\
\hline August & 3 & -7.1 & -2.37 & -3.61 & 1984 \\
\hline September & 3 & -5.69 & -1.9 & -2.31 & 2009 \\
\hline June-to-Sept (Kiremt: SPI-4) & 4 & -8.03 & -2 & -2.32 & 2015 \\
\hline Feb-to-Sept (SPI-8) & 4 & -7.14 & -1.79 & -2.83 & 1984 \\
\hline
\end{tabular}

Severe drought events with SPI values between -1.5 and - 1.99 were also observed in March (1999 and 2000) and April (1991, 1999 and 2001). Moreover, the largest drought risk events (about 23 years) for February, March, April, and May were shown under the moderate drought intensity class. Nevertheless, 6 and (2) years were under the severe and (extreme) drought intensity classes. Drought ends when the SPI value becomes positive while drought begins when SPI value becomes negative. Since drought ends when the SPI value becomes positive, the increasing drought frequency of February found to be by far the highest (Table 2). This increasing drought frequency of February was substantiated by a significant decline of rainfall as revealed in the MK trend test (Table 3) and regression trend line (Fig. 2a).
Similarly, Fig. 3a-d and Fig. 4b signify a mix of drought and wet frequencies in the timesteps of SPI1-month observations (June, July, August and September) and SPI4months of the current season. A mix of dry and wet years have been observed in June, July, August, and September as well as kiremt season but with temporal variation in severity, duration, magnitude, and intensity. It was witnessed from Fig. 3a-d and Fig. 4b extreme drought events with SPI $\leq-2$ were investigated in July 1987 and 2015, August 1984 and 1993, September 2009 and kiremt season of 1984, 1987 and 2015. Severe drought also was detected in June 1981, July 1981 and 1984, and September 1984. Moreover, moderate drought events were detected in June 1982, 1985, 1987, 1988 and 2017, July 1992, August 1990 and September 1997. It

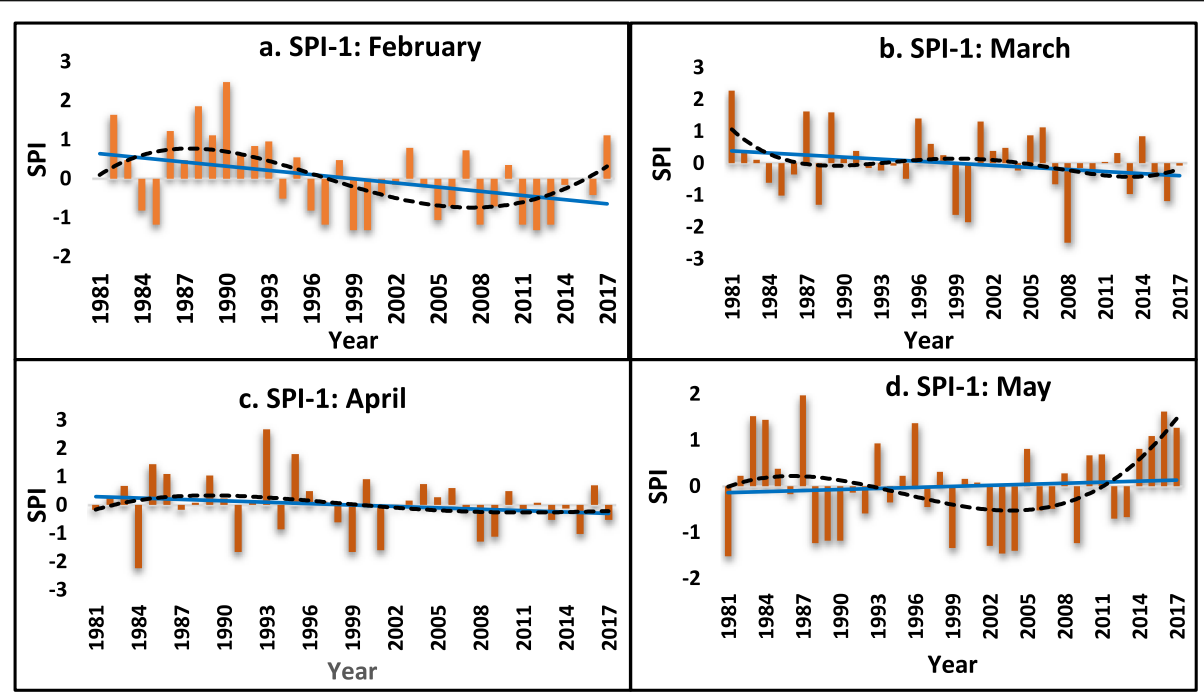

Fig. 2 SPI 1-month anomalies and trends of belg rainy months: (a) SPI-1: February; (b) SPI-1: March; (c) SPI-1: April; (d) SPI-1: May 
Table 3 Mann-Kendall's trend analysis and the probability of drought events per 100-year for the rainy months and seasons at 1-, 4and 8-months timesteps

\begin{tabular}{|c|c|c|c|c|c|}
\hline SPI timesteps & Months/Season & MK test & $P$-values & Slope & Probability of drought events per a 100-year \\
\hline \multirow[t]{8}{*}{ 1-month } & February & $-0.2539 * *$ & 0.0305 & -0.0366 & 24 \\
\hline & March & -0.1388 & 0.2337 & -0.0189 & 14 \\
\hline & April & -0.1508 & 0.1952 & -0.02 & 19 \\
\hline & May & 0.0693 & 0.556 & 0.0149 & 24 \\
\hline & June & $0.2493^{* *}$ & 0.0327 & 0.0311 & 16 \\
\hline & July & 0.1851 & 0.1105 & 0.0291 & 14 \\
\hline & August & 0.1458 & 0.2092 & 0.0188 & 8 \\
\hline & September & -0.0532 & 0.6559 & -0.0077 & 8 \\
\hline \multirow[t]{2}{*}{ 4-month } & Feb-to-May & -0.1583 & 0.1736 & -0.0248 & 11 \\
\hline & June-to-Sept & 0.2122 & 0.067 & 0.0281 & 11 \\
\hline 8-month & Feb-to-Sept & 0.1414 & 0.2238 & 0.0161 & 11 \\
\hline
\end{tabular}

Note: ** is statistically significant at $P<0.05$

was also shown in Fig. 4c that moderate drought event was detected in 2009 while extreme droughts were detected in 1984 and 2015 during the long-term rainy season of SPI 8-month timestep. Furthermore, the largest drought event years (about 8 years) for June, July, August and September were shown under the moderate drought intensity class while three and (six) years were under the severe and (extreme) drought intensity classes. Seasonally, belg and (kiremt) were under severe and (extreme) drought intensity classes for 3 years while 2 years of the long-term season (SPI8-months) were under extreme drought intensity class. However, values of SPI1(June, July, August) months and SPI 4- months (kiremt season) showed increasing trends except SPI1-month of September.
Incidences of drought trends and its probability per 100 -years over the small and big rainy months (SPI-1) and seasons (SPI-4 and SPI-8) timesteps were shown (Table 3). The Mann-Kendall trend test of SPI-values showed statistically significant decreasing and (increasing) trends for small and (big) rainy months of February and (June) at $p<0.05$. However, the 1-month timestep values of March, April, September and 4-month timesteps of February-to-May showed statistically nonsignificant decreasing rends. The 1-month timestep values of May, July, August, and 4-month timestep (June-to-September) on the other hand showed statistically non-significant increasing trends. The 8-month long-term seasonal timestep (Feb-to-Sept) value also showed a statistically non-significant increasing trend.

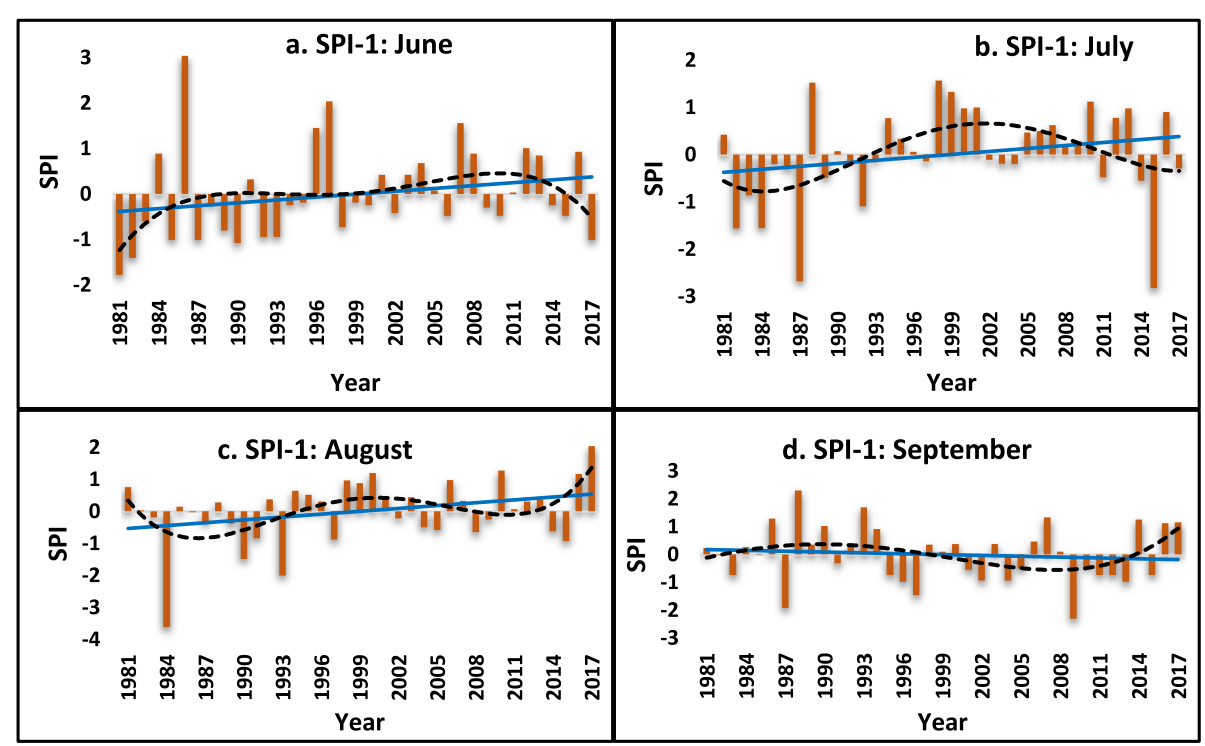

Fig. 3 SPI 1-month anomalies and trends of kiremt rainy months: (a) SPI-1: June; (b) SPI-1: July; (c) SPI-1: August; (d) SPI-1: September 


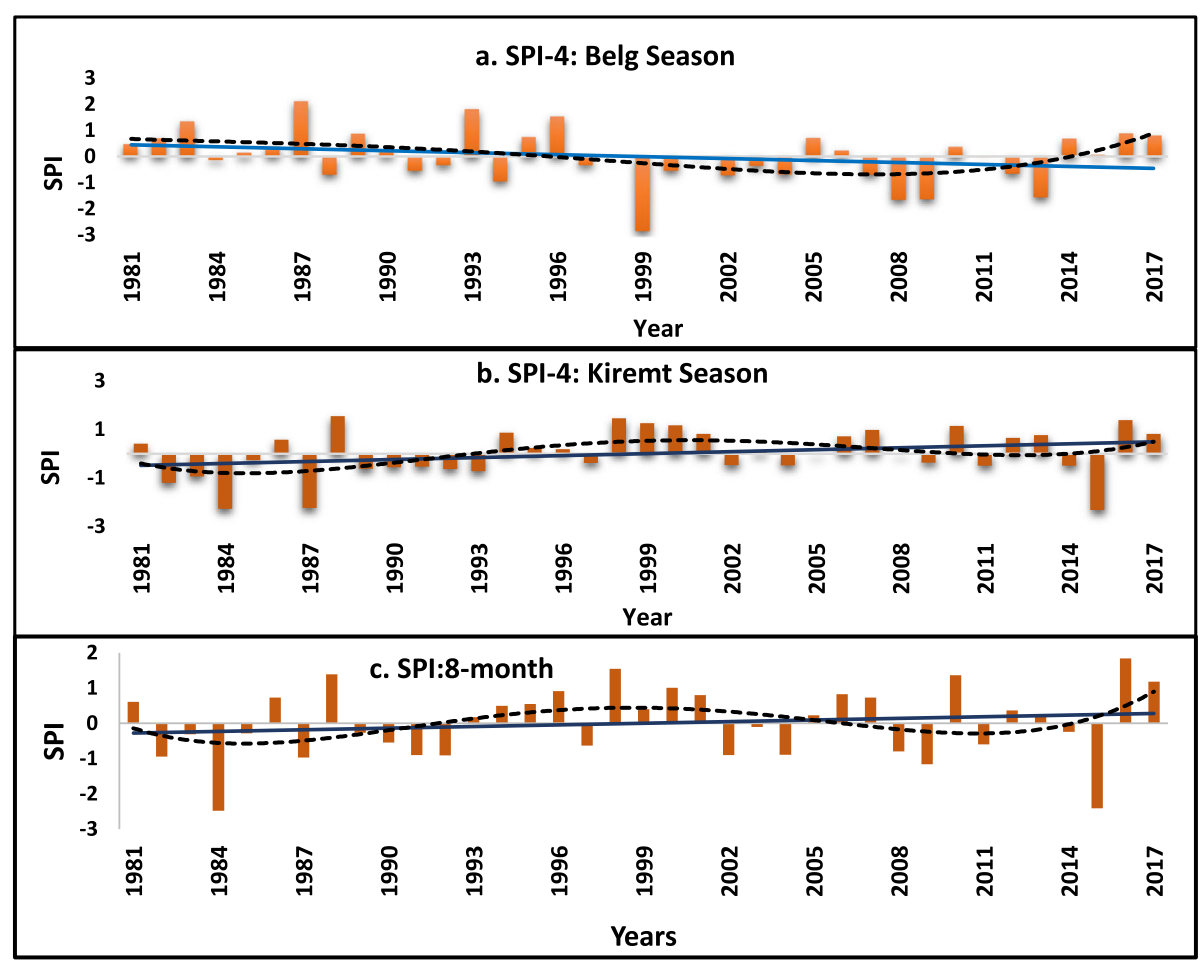

Fig. 4 The SPI anomalies and trends of the rainy seasons. a SPI-4: belg season (February-to-May); b SPI-4: kiremt season (June-to-September) and c SPI-8 long-term seasons (February-to-September)]

The predicted number of droughts for 100 years rainy months and seasons timesteps of 1-, 4- and 8-months based on eq. (4) is also presented (Table 3). The maximum predicted drought frequency events (except for August and September) were expected to be in the shorter timesteps of 1-month as compared to 4- month and 8-month timesteps. The 1-month predicted drought frequency events expected to be between 24 and (8) years for February and May and (for August and September). The seasonal predicted drought frequency events of all the 4-month (Feb-to-May and June-to-Sept) and 8-month (Feb-to-Sept) expected to be 11 years.

\section{Spatial patterns of drought incidence}

The spatial patterns of drought frequency incidence maps for 1-, 4- and 8-months timesteps for moderately dry-to- extremely dry intensity classes of drought events were depicted in Figs. 5, 6 and 7. The spatial pattern of drought risk frequency maps over the livelihood zones in the small rainy months (February, March, April, and May) was exhibited complex and high local-scale variation as indicated in Fig. 5. All the livelihood zones (ABB, Meher, Belg, CHV, Meher-Belg, and SWS) except around the station of Amba Mariam exposed to more frequent drought risks ranged from 9 years $(24 \%)$ to 12 years $(33 \%)$ of the total observation years. The drought frequency of March found to be higher in the northern, western and southern parts of the ABB, Meher, Belg, Meher-Belg livelihood zones that ranged from 6 years (15\%) to 8 years $(21 \%)$ of the total observation periods. Except for the areas around the stations of Kelala and Wereillu, which experienced the highest drought risks (8-9 years) in the south, the remaining livelihood zones' drought frequency during April varied from 6 years $(15 \%)$ to 7 years $(18 \%)$ of the total study periods. Similarly, the eastern part including ABB, Meher-Belg, SWS, Meher, CHV, and Belg livelihood zones and the western part of ABB, Meher experienced frequent drought risks ranged from $9(24 \%)$ to 11 years (30\%) of the total study years during May.

The spatial pattern of drought frequency maps in the big rainy months (June, July, August, and September) also revealed the complex and high local-scale variation as indicated in Fig. 6. It was found that all the livelihood zones except the eastern and southeastern periphery ( $\mathrm{ABB}$, Belg, and $\mathrm{CHV}$ ) experienced more frequent drought risks ranged from 7 years (18\%) to 9 years (24\%) of the observation periods during June. More frequent drought events ranged from 6 to 7 years, which accounts between 15 and $18 \%$ experienced during July in the northwest, southern and northern parts of Meher, ABB, Meher-Belg, SWS, and Belg livelihood zones. The incidences of drought frequency during August were found to be ranged from 3 years $(6 \%)$ to 6 years $(15 \%)$ in the 


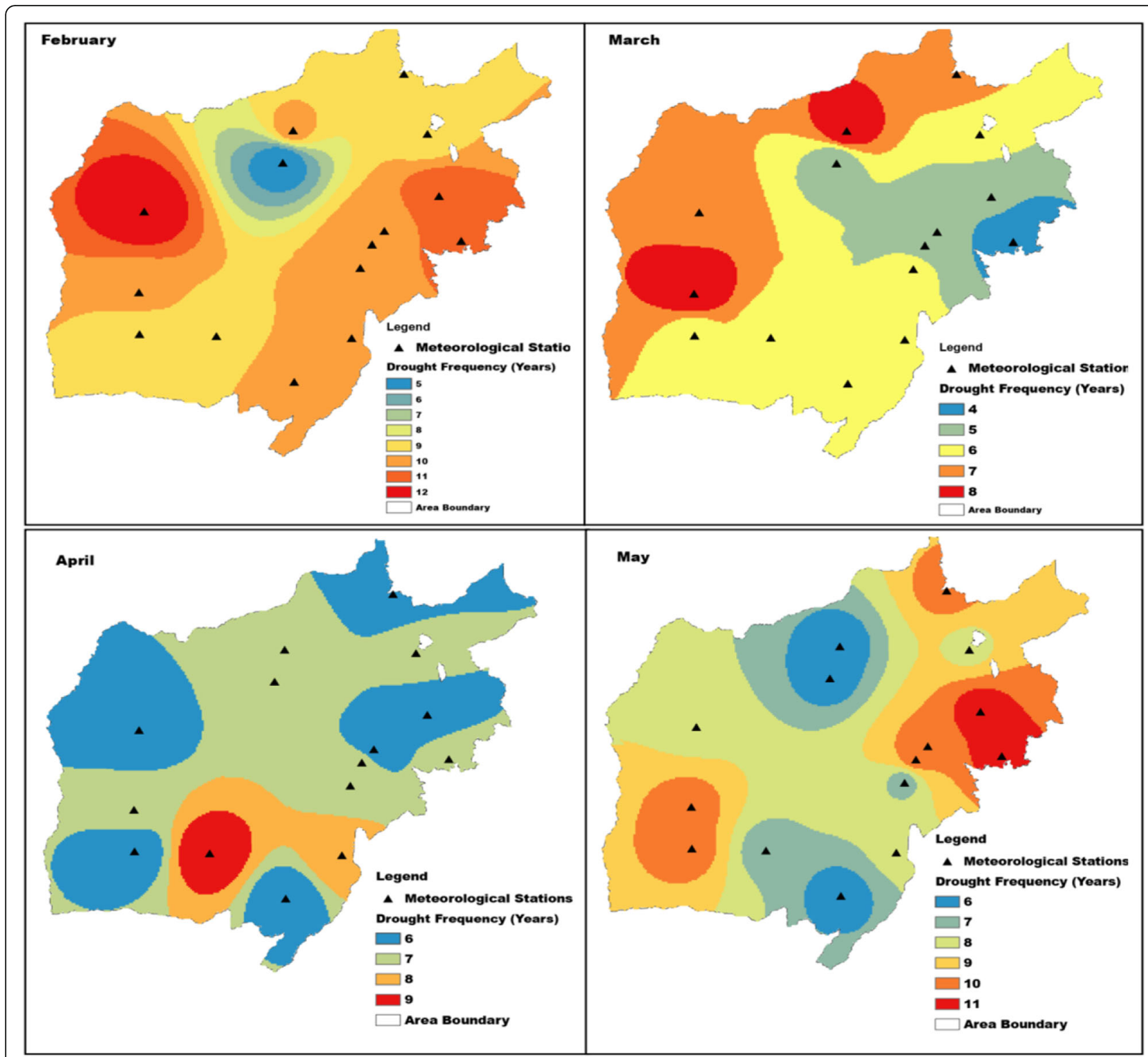

Fig. 5 The 1-month timesteps spatial pattern of drought frequency events (SPI $\leq-1.0)$ for the small rainy months of February, March, April, and May

eastern half including all the livelihood zones while the western half, including $\mathrm{ABB}$ and Meher livelihood zones covered about 7 years (18\%) and 9 years $(24 \%)$ of the study period. During September, the incidence of drought frequency was found to be more pronounced in the northeastern and southwestern parts including $\mathrm{ABB}$, Meher, Belg, and Meher-Belg livelihood zones that varied from 7 years $(18 \%)$ to 9 years (24\%). However, incidences of drought frequency varied between 4 years (9\%) and 6 years (15\%) in the northwestern, southern and southeastern parts including ABB, Meher, Belg, Meher-Belg, CHV, and SWS livelihood zones of the study area.
Figure 7 presents the spatial pattern of drought frequency maps for 4- and 8-months timesteps of belg and kiremt, and the long-term (both belg and kiremt). The SPI4-months of belg season the northern half, including Belg, Meher-Belg, CHV, and SWS livelihood zones (where belg crop harvesting dominate) experienced drought frequency events varied from 4 to 6 years (9$15 \%)$ while the southern half, including ABB and Meher livelihood zones experienced 7-9 years (18-24\%) of drought frequency events of the total observation periods. Conversely, during SPI:4-months of kiremt season, the southern half comprising part of ABB, Meher, Belg, and $\mathrm{CHV}$ livelihood zones (where kiremt season crop 


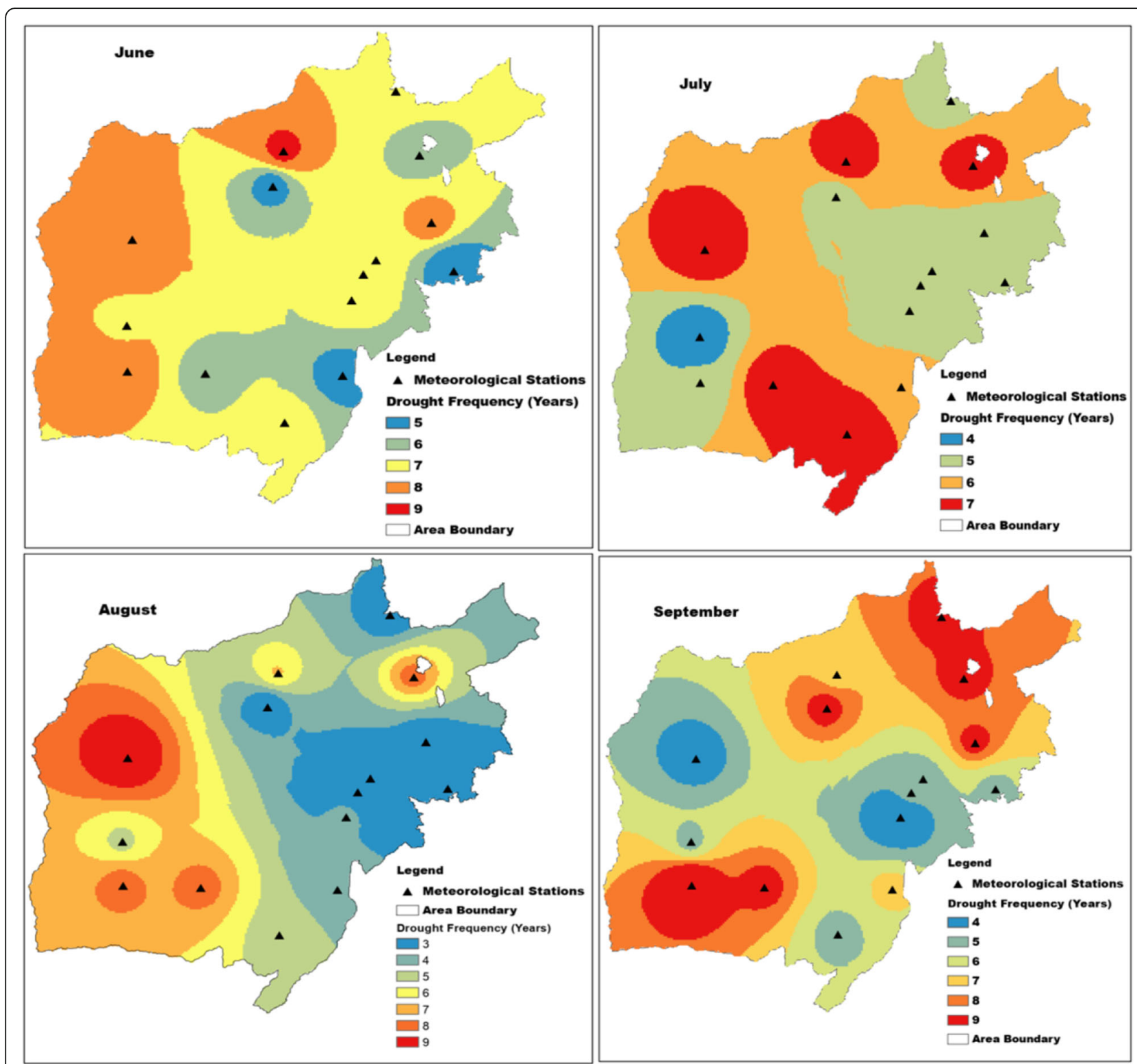

Fig. 6 The 1-month timesteps spatial pattern of drought frequency events (SPI $\leq-1.0)$ for the big rainy months of June, July, August, and September

harvesting dominate) experienced 5-7 years (12-18\%) drought frequency incidences while the northern covering parts of ABB, Meher, Belg, Meher-Belg, SWS, and CHV were experienced 8-11 years (21-30\%) of drought frequency events of the total observation periods. The long-term spatial tendency of drought incidences (February-to-September) were also observed in SPI:8months. Almost the eastern half except around the stations of Wuchalle and Kombolcha, experienced 8-9 years (21-24\%) drought frequency incidences. The southern and western parts on the other hand experienced 5-7 years (12-18\%) drought frequency occurrences of the total study periods.

\section{Discussion}

The rainfed agricultural activities of the study area depend on two rainy seasons: belg and kiremt. However, the incidence of drought disaster due to the shortfall of rainfall was the most important concern of this study. In this study, the temporal and spatial spread of drought frequency, magnitude, intensity and severity have been examined. Of the total observation years, the highest drought frequency was detected for February. The study results indicated that March 2008 and April 1984 were the most severe drought months. However, the belg season in 1999 was the driest year during the record. In agreement with this, Conway (2000a, 2000b) and Viste 


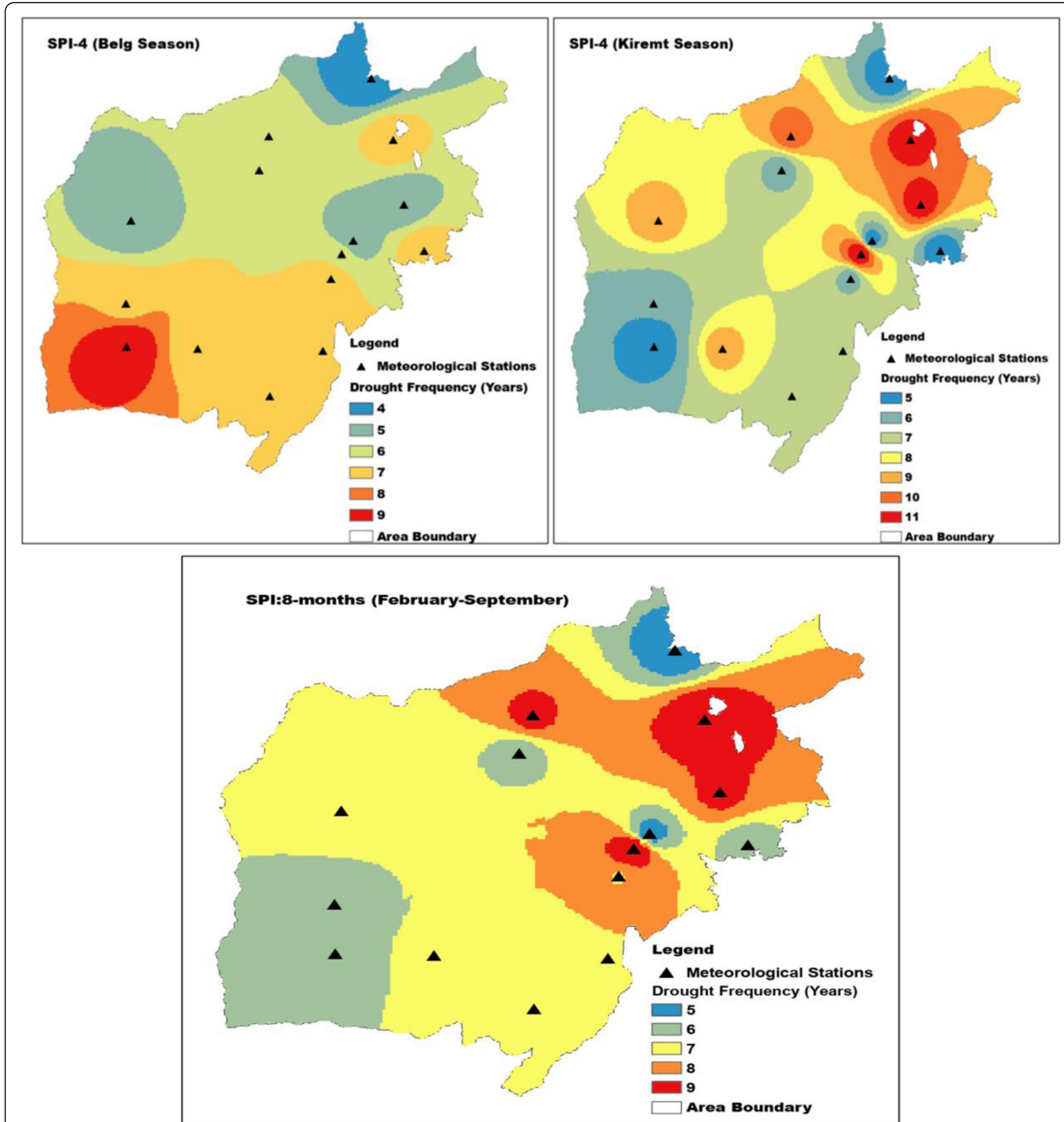

Fig. 7 The spatial pattern of drought frequency events (SPI $\leq-1.0)$ for SPI: 4- month (Feb-to-May, belg); SPI: 4- month (June-to-Sept, kiremt); and SPI: 8-month (Feb-to-Sept) timesteps

et al. (2013) reported that the belg season in 1999 was the driest year during the record over Ethiopia. A general tendency of increasing drought risk frequency has been observed in the study period of belg rainy months and season. The MK test for belg rainy months and season (1-and 4-months) timesteps also verifies the general decline of rainfall. Lyon and DeWitt (2012) and Lyon (2014) also showed the decline of rainfall or increase frequency of drought incidences for March-to-May months. The increasing of drought incidences in the 4months belg season was detected due to a rainfall deficit in the rainy months of February-to-May. The relative abrupt decline was seen since 1996, which is concurrent to Funk et al. (2005) at the national level. Multiple study reports in agreement with this study revealed that the greatest continual decline of rainfall has occurred during 
the belg season in the post-1980s (Tierney and Ummenhofer 2015; Funk et al. 2008; Funk et al. 2005). For example, in 1984, 72\% of Ethiopia's regions were affected by drought in the belg season (Shanko and Camberlin 1998).

Likewise, the highest drought frequency was observed in June during the big rainy months. However, extremely severe droughts were detected in August 1984, July 1987 and 2015, and September 2009. Thus, 1984, 1987 and 2015 were the three driest years in the record. Drought risk frequency and magnitude were more pronounced during the months of belg as compared to kiremt. Nonetheless, the drought risk intensity was more weighted during the months of kiremt. In agreement of this, Viste et al. (2013), Segele and Lamb (2005) reported that the kiremt season of 1982, 1984 and 1987 was severely dry over Ethiopia, particularly in the northeastern half of the country, which primarily caused by the missing rain in July and August. Lyon (2014) also revealed that the kiremt season (June, July, and August) rainfall during 1982 and 1984 was below-average rainfall for prolonged drought events that lead to the most devastating impact for 1950-2010 in northern Ethiopia. Further, Jjemba et al. (2017) and Philip et al. (2017) reported that the worst drought of 2015-16 in the northern and central part of Ethiopia because of belg rains had failed and soon after, kiremt rains were severely delayed, erratic and below the long-term average (deficit of $167 \mathrm{~mm}$ ). Segele and Lamb (2005) also revealed that the greatest damaging droughts in Ethiopia are connected with the failure of kiremt rains. Specifically, Suryabhagavan (2017), testified that South Wollo as one of the highest peaks of drought recorded area in 1984. A general decreasing trend tendency of drought events has been observed during 1-, 4- and 8-months timesteps of kiremt season. The MK test also confirms increasing trend tendencies, but it was only statistically significant for June.

A cyclical oscillation of wetter and drier events has shown in 1-, 4- and 8-months timesteps. Wetter conditions were illustrated in the period of the 1990s. In contrast, increasing drought risk event frequencies were illustrated in the 1980s and 2000s (Fig. 3b-c) and (Fig. 4b-c). In corroboration of this, for the 1970s onwards, drought has occurred during kiremt season in 1982, 1984, 1897, 1990, 1991, 1995, 1997, and 2002 due to the deficit of rainfall in June, July, August, and September (Conway 2000a, 2000b; Korecha and Barnston 2007). The influence of rainfall deficit during the kiremt season affects a significant portion of the county. For instance, in 1984 about $53 \%$ of the regions of Ethiopia were affected by drought in the kiremt season (Shanko and Camberlin 1998).

The 8-month long-term time step (Feb-to-Sept) demonstrated the drought events for the 1980s and 20002015. The 1984 and 2015 were the foremost terrible years on the record (Fig. 4c). Similarly, Funk et al. (2005) reported that 1984 stands the main horrible year on the record although the 1997, 2002 and 2004 undergone poor rainfall in the long-term (March-to-Sept), belg and kiremt seasons. March-to-Sept rainfall totals have also exhibited dry periods in the mid-1980s and mid-2000s. The drought risk events of months in the belg season were threefold greater than the months in kiremt season under moderate drought intensity class. Conversely, the drought risk events of months in kiremt season were threefold greater than that of the belg season under extreme drought intensity class.

In the 100-years, the predicted drought frequency events for 1-month timesteps were relatively more frequent than the 4-and 8-months seasonal timesteps except for August and September. In agreement with this, Łabędzki (2007) and Degefu and Bewket (2015) reported that drought events of shorter timesteps occur more frequently and last a shorter time than drought events of longer timesteps, which are more concentrated and last longer (changes slowly). However, Sternberg et al. (2011) reported contrasting results that frequency of drought events have been the lowest at 1-month timesteps and highest for the longer 17-months timestep.

The spatial distribution of drought frequencies was exhibited by the presence of complex patterns for 1-, 4-, and 8-months (Figs. 5, 6 and 7). The northern and (southern) half during 4-month belg and (kiremt) seasons experienced less frequent drought risk events. Conversely, the southern and (northern) half during 4month belg and (kiremt) seasons experienced a higher frequency of drought events. Almost the eastern half except around the stations of Wuchalle and Kombolcha, experienced the most drought frequency events while the southern and western parts experienced less drought frequency occurrences during the long-term 8-month timestep. In this regard, belg, and long-term (in both belg and kiremt) seasons crop harvesting areas were more exposed to frequent drought risks. The 4-month of kiremt season drought frequency pattern influenced and manifested over the 8-months drought frequency spatial pattern.

\section{Potential implications of drought incidences}

The SPI values of the rainy months of 1 -month as well as 4- and 8-months timesteps had an illustrious impact on the rainfall of the study periods that reflects the prompt occurrence of agricultural drought. In this regard, Łabędzki (2007) confirmed that the 1- to 6-months timesteps of SPI values soundly reflects well the quick development of agricultural drought, the exacerbating of the actual state of water conditions and the negative effects of rainfall deficit in agriculture (soil moisture, groundwater table depth, crop yield). The recurrent 
incidence of droughts for 1-, 4-, and 8-months has important implications on the socio-economy of rainfed agricultural practices and productions for smallholder farmers. The incidences of drought owing to the shortfall of rainfall during the months of belg (Feb-to-April), kiremt (June-to-Sept) and long-term rain (Feb-to-Sept) seasons were influencing the agricultural production. The greatest drought risk incidence of months in the belg and (kiremt) seasons under moderate and (extreme) drought intensity classes highly impacted the agricultural practices. The influence of moderate and extreme drought risk expected to be via the timely deficit of rain at planting and critical stage of crop growing that finally exposed the society to shift to food aid. For example, the reports of Viste et al. (2013), Block (2008), Prasad and Staggenborg (2009), World Bank (2006a, 2006b) and United Nations Environment Program/UNEP (2011) revealed that from the 1970s onwards, the decline of rainfall amount and the increasing frequency of drought directly influenced water shortages and limited crop growth and development, and reduced yield. This further threatened millions of people in the country that demanded emergency humanitarian assistance. In relation to this, Webb et al. (1992), Von Braun (1991), and Webb and Von Braun (1990) also indicated that the primary effects of drought on crop production and yields were quite strong. For instance, a 10\% decline in rainfall results in an average reduction in cereal yields of about $4.2 \%$.

The deficit of February-to-May rainfall is also be threatening those slowly maturing long-cycle crop production like sorghum and maize in the long-cycle crop growing areas of the study planted during belg and harvested after kiremt seasons. Degefu (1987) and Funk et al. (2005) report that poor belg season rainfall performance not only affecting belg crops but also adversely impacting the long-season crop production such as sorghum and maize, the country's major food crops. The detected incidence of drought risks of 8-months (Feb-toSept) was also influencing the long-cycle crop production such as Sorghum, Maize, and Millet growing areas (Meher-Belg livelihood zones) owing to deficit of rainfall in belg and kiremt seasons. In this regard, Funk et al. (2012) revealed that insufficient amount of belg and kiremt rainfall likely have negative impacts on agricultural production of slowly maturing varieties of crops (Maize, Sorghum, and Millet) and food availability. Mahoo et al. (2013) also reported that recurrent drought, changes in the consistent crop planting and shift in crop types, as well as rainfall variability related with the amount, timing, and intensity, are impacting the agricultural practices leading to frequent crop failures, losses of life and property. This means that more frequent droughts, and drier climate in general, maybe producing repeated shocks that increase vulnerability and then step up to a cycle of poverty (Funk et al. 2012). Mekonen and Berlie (2019) and McSweeney et al. (2008) also reported that the respective decreasing and increasing trends of rainfall and temperature were the potential threats to the agricultural sector through pest intensification.

\section{Conclusions}

This study presented the spatiotemporal drought risk events in the northeastern highlands of Ethiopia using Standardized Precipitation Index, SPI. The results of the study confirm that highly complex and localized temporal and spatial patterns of drought risk events were detected. This helped to identify and characterize local droughts. The majority of 1-4- and 8-months timestep underwent severe and extreme $(\mathrm{SPI} \leq-1.50)$ drought events. However, the detected frequency and magnitude of drought risk events were more pronounced during the rainy months of the belg season.

The 1-month belg and (kiremt) rainy months experienced the largest drought risk events under the moderate and (extreme) drought intensity classes. Moreover, the 4month belg and (the 4- month kiremt and 8-month longterm) seasons experienced the largest drought risk events under the severe and (extreme) drought intensity classes. Increased drought risk frequency events were observed in the 1980s and 2000s onwards for kiremt and long-term seasons. A steady increased drought risk event frequency was detected since 1980s during belg season. In the spatial pattern of drought, the southern part during belg, the northern and eastern during kiremt and the eastern half during the long-term rainy seasons experienced more frequent drought risk events.

The observed temporal and spatial drought risk events indicate a potential threat to the rainfed agricultural practices that gradually jeopardized the smallholder farmers to food insecurity and socio-economic vulnerability. The findings of this study also could be a rudimentary stage to enhance drought risk management strategy through the appraisal of the rainfed agricultural practices in the study area. Therefore, the documentation and informed assessment of drought frequency, magnitude, intensity and severity based on the livelihood zones are essential for drought risk management, early warning responses, local-scale planning, and food security management. Finally, the study recommended further research on additional indices of climatic variables such as evapotranspiration and soil water content.

\section{Abbreviations}

ANRSPC: Amhara National Regional State Plan Commission; CRED: Center for Research on the Epidemiology of Disaster; IPCC: Intergovernmental Panel on Climate Change; MK: Mann Kendal; NMSA: National Meteorological Service Agency; PDSI: Palmer Drought Severity Index; SPI: Standardized Precipitation Index; SWAD: South Wollo Agriculture Department; UNEP: United Nations 
Environmental Program; WFP: World Food Program; WMO: World Meteorological Organization

\section{Acknowledgments}

We are grateful to the Ethiopian National Meteorological Agency-East Amhara Meteorological service center (Kombolcha) for providing us the monthly rainfall data. We are also indebted to the two anonymous reviewers for their insightful and thoughtful feedback for further improvement of the manuscript.

\section{Authors' contributions}

The first author collects and analyzes the data, and wrote the manuscript. All authors read, edit and approved the manuscript.

\section{Funding}

The first author is grateful to Bahir Dar and Debremarkos Universities for funding support as part of his PhD study.

\section{Availability of data and materials}

The datasets used and/or analyzed during the current study are available from the corresponding author on reasonable request.

\section{Competing interests}

The authors declare that they have no competing interests.

Received: 9 August 2019 Accepted: 28 January 2020

Published online: 03 March 2020

\section{References}

AghaKouchak A, Nakhiiri N (2012) A near real-time satellite-based global drought climate data record. Environ Res Lett 7(4):044037. https://doi.org/10.1088/ 1748-9326/7/4/044037

ANRSPC (2017) Amhara National Regional State Plan Commission 2015/2016 budget year annual statistical bulletin, Ethiopia

Ashraf M, Routray JK (2013) Perception and understanding of drought and coping strategies of farming households in north-West Balochistan. Int J Dis Risk Reduct 5:49-60. https://doi.org/10.1016/j.jjdrr.2013.05.002

Bannayan M, Sanjani S, Alizadeh A, Lotfabadi SS, Mohamadian A (2010) Association between climate indices, aridity index, and rainfed crop yield in northeast of Iran. Field crops research 118(2):105-114. https://doi.org/10. 1016/j.fcr.2010.04.011

Beth L, Brown TJ (2003) A comparison of precipitation and drought indices related to fire activity in the US. In: 5th symposium on fire and Forest meteorology

Block PJ (2008) An assessment of investments in agricultural and transportation infrastructure, energy, and hydroclimatic forecasting to mitigate the effects of hydrologic variability in Ethiopia. In: CPWF working paper 01 the CGIAR challenge program on water and food, Colombo, Sri Lanka, p 53

Bussay AM, Szinell C, Hayes M, Svoboda M (1998) Monitoring drought in Hungary using the standardized precipitation index. In: Annales Geophysicae, Supplement (Vol. 11)

Butterfield R (2011) Climate changes in East Africa https://www.weadapt.org/ knowledge-base/national-adaptation-planning/climate-changes-in-east-africa

Centre for Research on the Epidemiology of Disasters/CRED (2016) International disaster database http://www.emdat.be/disaster_profiles/index.html

Chattopadhyay S, Edwards DR (2016) Long-term trend analysis of precipitation and air temperature for Kentucky, United States. Climate 4(1):10. https://doi. org/10.3390/cli4010010

Conway D (2000a) Some aspects of climate variability in the northeast Ethiopian highlands-Wollo and Tigray. Sinet: Ethiopian J Sci 23(2):139-161. https://doi. org/10.4314/Sinet. v23i2.18163

Conway D (2000b) The climate and hydrology of the upper Blue Nile River. Geogr J 166(1):49-62. https://doi.org/10.1111/j.1475-4959.2000.tb00006.x

Dai A (2011) Drought under global warming: a review. Wiley Interdiscip Rev Clim Chang 2(1):45-65. https://doi.org/10.1002/wcc.81

Degefu MA, Bewket W (2015) Trends and spatial patterns of drought incidence in the Omo-Ghibe River basin, Ethiopia. GeografiskaAnnaler: Ser A, Phys Geograph 97(2):395-414. https://doi.org/10.1111/geoa.12080

Degefu W (1987) Some aspects of meteorological drought in Ethiopia. Cambridge University Press, Cambridge, pp 23-36

Dorosh P, Rashid S (2013) Food and agriculture in Ethiopia: Progress and policy challenges. University of Pennsylvania Press, Philadelphia. International Journal of the Commons, 7(2):573-574. https://doi.org/10.18352/ijc.448
Edossa DC, Babel MS, Gupta AD (2010) Drought analysis in the awash river basin, Ethiopia. Water Resour Manag 24(7):1441-1460. https://doi.org/10.1007/ s11269-009-9508-0

Endale D (1993) The Ethiopian famines, entitlements, and governance. World Institute for Development Economics Research of the United Nations University, Annankatu 42 C, 00100 Helsinki, Finland. Working papers No. 102

Funk C, Dettinger MD, Michaelsen JC, Verdin JP, Brown ME, Barlow M, Hoell A (2008) Warming of the Indian Ocean threatens eastern and southern African food security but could be mitigated by agricultural development. Proc Natl Acad Sci 105(32):11081-11086. https://doi.org/10.1073/pnas.0708196105

Funk C, Rowland J, Eilerts G, Kebebe E, Biru N, White L, Galu G (2012) A climate trend analysis of Ethiopia. In: US Geol Surv, Fact Sheet, p 3053

Funk C, Senay G, Asfaw A, Verdin J, Rowland J, Michaelson J et al (2005) Recent drought tendencies in Ethiopia and equatorial-subtropical eastern Africa. FEWS-NET, Washington DC

Gautam M (2006) Managing drought in sub-Saharan Africa: policy perspectives. Invited paper prepared for presentation at the International Association of Agricultural Economists, Gold Coast, Australia

Gebrehiwot T, van der Veen A, Maathuis B (2011) Spatial and temporal assessment of drought in the northern highlands of Ethiopia. Int J Appl Earth Obs Geoinf 13(3):309-321. https://doi.org/10.1016/j.jag.2010.12.002

Ghosh KG (2019) Spatial and temporal appraisal of drought jeopardy over the Gangetic West Bengal, eastern India. Geoenviron Disas 6(1):1. https://doi.org/ 10.1186/s40677-018-0117-1

Gommes R, Petrassi F (1996) Rainfall variability and drought in sub-Saharan Africa SD dimensions, FAO

Guha-Sapir D, Vos F, Below R, Ponserre S (2012) Annual disaster statistical review 2011: the numbers and trends Centre for Research on the Epidemiology of Disasters (CRED)

Guttman NB (1998) Comparing the palmer drought index and the standardized precipitation index. JAWRA J Am Water Resour Assoc 34(1):113-121. https:// doi.org/10.1111/j.1752-1688.1998.tb05964.x

Guttman NB (1999) Accepting the standardized precipitation index: a calculation algorithm 1. JAWRA J Am Water Resour Assoc 35(2):311-322

Hao Z, AghaKouchak A, Nakhjiri N, Farahmand A (2014) Global integrated drought monitoring and prediction system. Scientific data 1:140001. https:// doi.org/10.1038/sdata.2014.1

Hayes M, Svoboda M, Wall N, Widhalm M (2011) The Lincoln declaration on drought indices: universal meteorological drought index recommended. Bull Am Meteorol Soc 92(4):485-488. https://doi.org/10.1175/2010BAMS3103.1

Hayes MJ, Svoboda MD, Wiihite DA, Vanyarkho OV (1999) Monitoring the 1996 drought using the standardized precipitation index. Bull Am Meteorol Soc 80(3):429-438

Jeyaseelan AT (2003) Droughts and floods assessment and monitoring using remote sensing and GIS. In: Satellite remote sensing and GIS applications in agricultural meteorology (Vol. 291). World Meteorol. Org. Dehra Dun, India Geneva

Jjemba E, Singh R, Arrighi J (2017) Extreme drought in Ethiopia stretches drought management systems

Kahsay B (2013) Diagnosis and intervention plans for south Wollo zone, Amhara region: livestock and irrigation value chains for Ethiopian smallholders (LIVES) Google Scholar

Kendall MG (1975) Rank correlation methods, 4th edn. Griffin, London

Khan MA, Gadiwala MS (2013) A study of drought over Sindh (Pakistan) using standardized precipitation index (SPI) 1951 to 2010. Pakistan J Meteorol 9(18):15-22

Korecha D, Barnston AG (2007) Predictability of June-September rainfall in Ethiopia. Mon Weather Rev 135(2):628-650. https://doi.org/10.1175/MWR3304.1

Łabędzki L (2007) Estimation of local drought frequency in Central Poland using the standardized precipitation index SPI. Irrigation and Drainage J Int Commission Irrigation Drain 56(1):67-77. https://doi.org/10.1002/ird.285

Little PD, Stone MP, Mogues T, Castro AP, Negatu W (2006) 'Moving in place': drought and poverty dynamics in south Wollo, Ethiopia. J Dev Stud 42(2): 200-225. https://doi.org/10.1080/00220380500405287

Loukas A, Vasiliades L (2004) Probabilistic analysis of drought spatiotemporal characteristics inThessaly region, Greece. Nat Hazards Earth Syst Sci 4(5/6):719-731

Lyon B (2014) Seasonal drought in the greater horn of Africa and its recent increase during the march-may long rains. J Climate 27(21):7953-7975. https://doi.org/10.1175/JCLI-D-13-00459.1

Lyon B, DeWitt DG (2012) A recent and abrupt decline in the east African long rains. Geophys Res Lett 39(2). https://doi.org/10.1029/2011GL050337

Mahoo H, Radeny M, Kinyangi J, Cramer L (eds) (2013) Climate change vulnerability and risk assessment of agriculture and food security in 
Ethiopia: which way forward? CCAFS working paper no. 59. CGIAR Research Program on Climate Change, Agriculture and Food Security (CCAFS), Copenhagen

Mann HB (1945) Nonparametric tests against trend. Econometrica 13:245-259

Marimon DC (2016) Contributions to the knowledge of the multitemporal spatial patterns of the Iberan peninsula droughts from a geographic information service perspective, Universitat Autònoma de Barcelona, PhD thesis. Accessed from https://www.tdx.cat/handle/10803/379829\#page=1.

Mashari Eshghabad S, Omidvar E, Solaimani K (2014) Efficiency of some meteorological drought indices in different time scales (case study: Tajan Basin, Iran). ECOPERSIA 2(1):441-453

Masih I, Maskey S, Mussá FEF, Trambauer P (2014) A review of droughts on the African continent: a geospatial and long-term perspective. Hydrol Earth Syst Sci 18(9):3635. https://doi.org/10.5194/hess-18-3635-2014

McKee, T. B., Doesken, N. J., \& Kleist, J. 1993. The relationship of drought frequency and duration to time scales. In Proceedings of the 8th conference on applied climatology. Boston, American Meteorological Society, (17)22, 179-183

McSweeney C, New M, Lizcano G (2008) UNDP climate change country profiles: Ethiopia Available from http://country-profiles.geog.ox.ac.uk

Mekonen AA, Berlie AB (2019) Spatiotemporal variability and trends of rainfall and temperature in the northeastern highlands of Ethiopia. Modeling Earth Syst Environ:1-16. https://doi.org/10.1007/s40808-019-00678-9

Mirza MMQ (2003) Climate change and extreme weather events: can developing countries adapt? Clim Pol 3(3):233-248. https://doi.org/10.1016/s14693062(03)00052-4

Morid S, Smakhtin V, Moghaddasi M (2006) Comparison of seven meteorological indices for drought monitoring in Iran. Int J Climatol 26(7):971-985. https:// doi.org/10.1002/joc.1264

Mpelasoka F, Hennessy K, Jones R, Bates B (2008) Comparison of suitable drought indices for climate change impacts assessment over Australia towards resource management. Int J Climatol 28(10):1283-1292. https://doi.org/10.1002/joc.1649

National Meteorological Services Agency of Ethiopia/NMSA, 1996. Climatic and agro-ecology resources of Ethiopia, Addis Ababa, Ethiopia, 1(1):0-137

Ntale HK, Gan TY (2003) Drought indices and their application to East Africa. Int J Climatol 23(11):1335-1357. https://doi.org/10.1002/joc.931x

Padhee SK, Nikam BR, Aggarwal SP, Garg V (2014) Integrating effective drought index (EDI) and remote sensing derived parameters for agricultural drought assessment and prediction in Bundelkhand region of India. Int Arch Photogram Remote Sensing Spatial Inform Sci 40(8):89. https://doi.org/10. 5194/isprsarchives-XL-8-89-2014

Philip S, Kew SF, Jan van Oldenborgh G, Otto F, O'Keefe S, Haustein K et al (2017) The drought in Ethiopia, 2015 climate and development knowledge network and world weather attribution initiative Raising Risk Awareness

Piechota TC, Dracup JA (1996) Drought and regional hydrologic variation in the United States: associations with the El Niño-southern oscillation. Water Resour Res 32(5):1359-1373. https://doi.org/10.1029/96WR00353

Prasad PV, Staggenborg SA (2009) Growth and production of sorghum and millets. soils, plant growth and crop production, 2. In: Encyclopedia of life support systems (EOLSS), developed under the auspices of the UNESCO

Segele ZT, Lamb PJ (2005) Characterization and variability of Kiremt rainy season over Ethiopia. Meteorol Atmos Phys 89(1-4):153-180. https://doi.org/10.1007/ s00703-005-0127-X

Seleshi Y, Camberlin P (2006) Recent changes in dry spell and extreme rainfal events in Ethiopia. Theor Appl Climatol 83(1):181-191. https://doi.org/10. 1007/s00704-005-0134-3

Seleshi Y, Zanke U (2004) Recent changes in rainfall and rainy days in Ethiopia. Int J Climatol A J R Meteorol Soc 24(8):973-983. https://doi.org/10.1002/joc.1052

Sen PK (1968) Estimates of the regression coefficient based on Kendall's tau. J Am Stat Assoc 63(324):1379-1389

Shanko D, Camberlin P (1998) The effects of the Southwest Indian Ocean tropical cyclones on Ethiopian drought. Int J Climatol 18(12):1373-1388

Sheffield J, Wood EF (2007) Projected changes in drought occurrence under future global warming from multi-model, multi-scenario, IPCC AR4 simulations. Climate dynamics 31(1):79-105. https://doi.org/10.1007/s00382-007-0340-z

Shiferaw B, Tesfaye K, Kassie M, Abate T, Prasanna BM, Menkir A (2014) Managing vulnerability to drought and enhancing livelihood resilience in sub-Saharan Africa: technological, institutional and policy options. Weather and Climate Extremes 3:67-79. https://doi.org/10.1016/j.wace.2014.04.004

Spinoni J, Naumann G, Carrao H, Barbosa P, Vogt J (2014) World drought frequency, duration, and severity for 1951-2010. Int J Climatol 34(8):27922804. https://doi.org/10.1002/joc.3875
Stagge JH, Tallaksen LM, Gudmundsson L, Van Loon AF, Stahl K (2015) Candidate distributions for climatological drought indices (SPI and SPEI). Int J Climatol 35(13):4027-4040

Sternberg T, Thomas D, Middleton N (2011) Drought dynamics on the Mongolian steppe, 1970-2006. Int J Climatol 31(12):1823-1830. https://doi.org/10.1002/ joc.2195

Suryabhagavan KV (2017) GIS-based climate variability and drought characterization in Ethiopia over three decades. Weather Clim Extremes 15: 11-23. https://doi.org/10.1016/j.wace.2016.11.005

SWAD (2018) South Wollo Zone Agricultural Department 2016/17 budget year annual report. SWAD, Dessie

Szalai S, Szinell CS (2000) Comparison of two drought indices for drought monitoring in Hungary — a case study. In: Drought and drought mitigation in Europe, pp 161-166

Thompson SA (1999) Hydrology for Water Management. CRC Press, London, pp 286-317. https://doi.org/10.1201/9780203751435

Tierney JE, Ummenhofer CC (2015) Past and future rainfall in the horn of Africa. Sci Adv 1(9):e1500682. https://doi.org/10.1126/sciadv.1500682

Trenberth K, Meehl J, Masters J, Somerville R (2011) Current extreme weather and climate change. Climate communication science and outreach

Tsakiris G, Vangelis H (2004) Towards a drought watch system based on spatial SPI. Water Resour Manag 18(1):1-12. https://doi.org/10.1023/B:WARM. 0000015410.47014.a4

United Nations Environment Program/UNEP (2002) Global environment outlook 3: past, present and future perspectives. Environ Manag Health 13(5):560-561

United Nations Environment Program/UNEP (2011) Food security in the horn of Africa: the Implicationsof a drier, hotter and more crowded future Ecosystem Management, Climate Change

USAID (2009) Ethiopia livelihood zones Accessed from http://www.fews.net/eastafrica/ethiopia/.livelihood-zone November, 2017

Viste E, Korecha D, Sorteberg A (2013) Recent drought and precipitation tendencies in Ethiopia. Theor Appl Climatol 112(3-4):535-551. https://doi. org/10.1007/s00704-012-0746-3

Von Braun J (1991) A policy agenda for famine prevention in Africa (no. 1) International food policy research institute (IFPRI)

Webb P, Braun JV (1994) Famine and food security in Ethiopia: lessons for Africa. Wiley, Chichester

Webb P, Braun JV, Yohannes Y (1992) Famine in Ethiopia: policy implications of coping failure at national and household levels. IFPRI research reports

Webb P, Von Braun JV (1990) Drought and food shortages in Ethiopia: a preliminary review of effects and policy implications International Food Policy Research Institute

WFP (2014) Resilience measurement principles: toward an agenda for measurement design. Technical series no.1

Wilhite DA (2000) Drought as a natural hazard: concepts and definitionsDrought Mitigation Center Faculty Publications, pp 69.3-69.18

Wilhite DA, Glantz MH (1985) Understanding: the drought phenomenon: the role of definitions. Water Int 10(3):111-120. https://doi.org/10.1080/ 02508068508686328

Williams AP, Funk C (2011) A westward extension of the warm pool leads to a westward extension of the Walker circulation, drying eastern Africa. Climate Dynam 37(11-12):2417-2435. https://doi.org/10.1007/s00382-010-0984-y

WMO (2009) Guide to hydrological practices, volume II, management of water resources and application of hydrological practices Extreme value analysis, WMO-No. 168

WMO (2012) Standardized Precipitation Index User Guide (M. Svoboda, M. Hayes and D. Wood). (WMO-No. 1090), Geneva

WMO (2016) Guidelines on the definition and monitoring of extreme weather and climate events

World Bank (2006a) Ethiopia: managing water resources to maximize sustainable growth. World Bank, Washington, D.C.

World Bank (2006b) IDA countries and exogenous shocks. International development association resource mobilization. World Bank, Washington, DC

Zhan W, Guan K, Sheffield J, Wood EF (2016) Depiction of drought over subSaharan Africa using reanalysis precipitation data sets. J Geophys Res Atmos 121(18):10,555-10,574. https://doi.org/10.1002/2016JD024858

\section{Publisher's Note}

Springer Nature remains neutral with regard to jurisdictional claims in published maps and institutional affiliations. 